\title{
PENGARUH PENAMBAHAN ABU SERABUT KELAPA TERHADAP KUAT TEKAN BETON
}

\author{
Nur Azizah Affandy ${ }^{1}$,Agus Imam Bukhori², \\ 1,2 Fakultas Teknik, Universitas Islam Lamongan \\ Email:nurazizah@unisla.ac.id;agusbukhori45642@gmail.com,
}

\begin{abstract}
Concrete is a composite material (mixture) of several materials, whose main material consists of a mixture of cement, fine aggregates, coarse aggregates, water and or without other added ingredients coconut fibers are only used for broom materials, rugs, ropes and household appliances. Therefore, the addition of burning concrete into coconut ash ash is tried.The method used was experimental carried out in the laboratory with the production of 12 test pieces with presentations of $0 \%, 0.25 \%, 0.5 \%$ and $0.75 \%$ at 7 days.Laboratory test results on the addition of coconut fiber ash to the normal $\mathrm{K} 100$ presentation were $16.505 \mathrm{MPa}$, coconut fiber ash mixture $0.25 \%$ reached $23.895 \mathrm{MPa}$, coconut fiber ash mixture $0.5 \%$ reached $23.656 \mathrm{MPa}$, the highest fiber ash mixture concrete $0.75 \%$ coconut can reach compressive strength of 23,688 MPa.
\end{abstract}

Keyword :Ash, Coconut Fiber, Compressive Strength, Concrete

\section{ABSTRAK}

Beton adalah bahan komposit (campuran) dari beberapa bahan, yang bahan utamanya terdiri dari campuran semen, agregat halus, agregat kasar, air dan atau tanpa bahan tambahan lainnya. Serabut kelapa hanya digunakan untuk bahan sapu, permadani, tali dan peralatan rumah tangga. Oleh karena $i t u$, penambahan pembakaran beton ke abu abu kelapa dicoba. Metode yang digunakan adalah eksperimental yang dilakukan di laboratorium dengan produksi 12 buah uji dengan presentasi $0 \%$, 0,25\%, 0,5\% dan 0,75\% pada 7 hari. Hasil uji laboratorium pada penambahan abu serabut kelapa dengan presentasi $\mathrm{K} 100$ normal adalah $16.505 \mathrm{MPa}$, campuran abu serabut kelapa 0,25\% mencapai 23.895 MPa, campuran abu serabut kelapa 0,5\% mencapai $23.656 \mathrm{MPa}$, beton campuran abu serat tertinggi 0,75\% kelapa bisa mencapai kekuatan tekan 23.688 MPa.

Kata kunci: Abu, Serat Kelapa, Kekuatan Tekan, Beton

\section{PENDAHULUAN}

Penggunaan beton sebagai bahan konstruksi diminati karena beton memiliki sifat-sifat yang menguntungkan, seperti ketahanannya terhadap api, awet, kuat tekan yang tinggi dan dalam pelaksanaannya mudah untuk dibentuk sesuai dengan bentuk yang dkehendaki (Candra, Gardjito, Cahyo, \& Prasetyo, 2019). Tetapi konstruksi beton juga mempunyai kelemahankelemahan, antara lain kemampuan menahan tarik yang rendah sehingga konstruksinya mudah retak jika mendapatkan tegangan tarik (Candra, n.d.).

Seiring dengan perkembangan zaman, berbagai inovasi telah dilakukan untuk memperbaiki performa beton sehingga muculah istilah-istilah seperti beton bertulang (reinforced concrete), beton pratekan (prestressed concrete) dan beton serat (fiber concrete)(Candra, n.d.) .

Pada penelitian ini bahan tambah yang digunakan adalah abu serabut kelapa. Abu serabut kelapa berasal dari pengolahan limbah serabut kelapa yang dibakar yang kemudian menjadi abu. Oleh karena itu, dilakukan penelitian untuk memanfaatkan limbah abu serabut kelapa menjadi bahan 
yang bermanfaat, yaitu sebagai bahan tambah dalam campuran beton. Melanjutkan penelitian yang dilakukan oleh. Nora Usrina, Rahmi Karolina, Johannes Tarigan alumni jurusan teknik sipil fakultas teknik Universitas Sumatera Utara, dimana telah dilakukan pencampuran abu serabut kelapa pada campuran beton untuk menguji dan mengetahui pengaruh penambahan abu serabut kelapa terhadap kuat tekan pada silinder.

Indonesia ini merupakan negara penghasil serabut kelapa terbesar di dunia dan indonesia masih belum mengelolah serabut kelapa dengan maksimal. Limbah padat khususnya serabut kelapa sampai saat ini belum dimanfaatkan secara optimal dalam membuat bahan tambahan bangunan. Serabut kelapa mempunyai potensi yang baik untuk dikembangkan sebagai bahan teknik dengan melakukan rekayasa material komposit.

Tujuan yang ingin dicapai dari kajian ini adalah:

1. Untuk mengetahui kuat tekan beton jika ditambahkan abu serabut kelapa.

2. Untuk mengetahui penambahan abu serabut kelapa dapat menaikan kuat tekan beton atau sebaliknya

\section{METODE PENELITIAN}

Penelitian ini dilakukan dilaboratorium Teknik SipilUniversitas Islam lamongan. Menggunakan pengujian langsung di laboraturium dengan metode ASTM (American Society for Testing and Material) untuk uji agregat.

Untuk campuran yang digunakan adalah abu serabut kelapa yang telah dijelaskan pada pendahuluan diatas.

\section{RencanaPenelitian}

Penelitian ini merupakan penelitian eksperimental di laboratorium. Adapun item penelitian yang akan dilakukan terdiri dari penelitian terhadap bahan susun beton dan penelitian terhadap kuat tekan beton.

Gambar 4. Flow Chat 


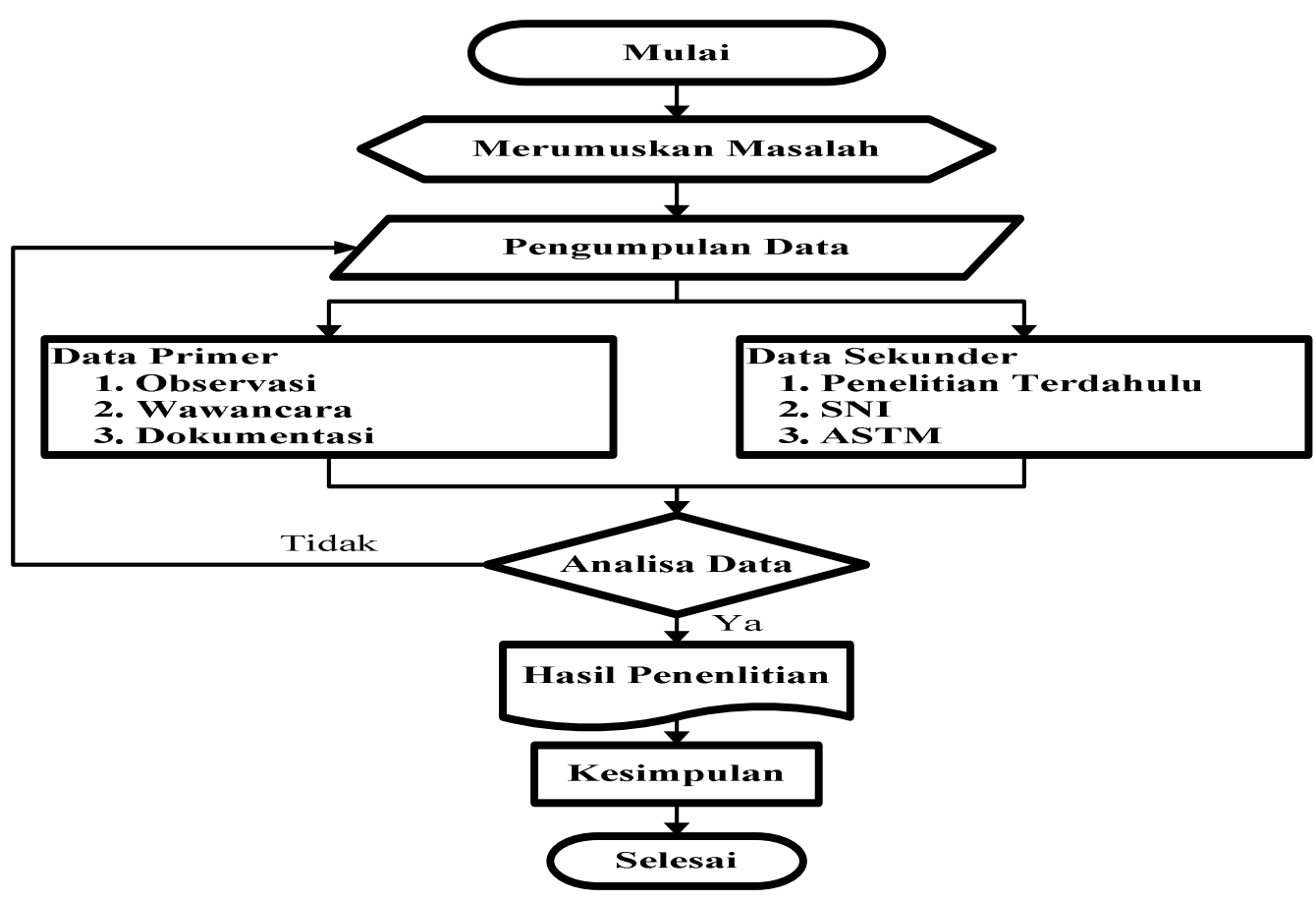

\section{PEMBAHASAN}

Untuk melancarkan penelitian ini peneliti melakukan kerja sama dengan tim di laboratorium teknik sipil fakultas teknik universitas islam lamongan, dari Hasil penelitian yang telah dilakukan menghasilkan beberapa hasil yaitu:

\subsection{Pengujian Semen}

a) Konsistensi Normal Semen Perland (ASTM C 187-86)

Diperoleh penurunan $10 \mathrm{~mm}$ sebesar 27,6 \% konsentensi. Menurut ASTM 187-89 kadar air dalam semen ketika terjadi penurunan $10 \mathrm{~mm}$ pada test konsentrasi normal dengan menggunakan alat vicat untuk mengetahui berapa air yang dibutuhkan agar semen mencapai kebasahan yang standart

b) Waktu Pengikatan Dan Pengerasan Semen (ASTM 119-92)

Pengikatan semen memerlukan waktu sebesar 225 menit hingga mengeras.

c) Berat Jenis Pasir (ASTM C 188-95)

Dari hasil pengujian beratjenis semen yang didapatkan yaitu sebesar 2,83. Berdasarkan ASTM C 188 - 95 berat jenis semen porland mempunyai besaran antara 3,0 - 3,2, jadi hasil pengujian tidak sesui.

\subsection{Pengujian Agregat Halus}

a) Test Kondisi Analisa Ayakan Pasir (ASTM C 136-84a) 
Didapatkan hasil sebesar 3,19. Modulus Halus Butir (MHB), syarat modulus halus butiran untuk beton menurut ASTM yaitu 2,20\% - 3,10\% MHB 2,5 s/d 3,0. Jadi hasil tidak memenuhi yang diinginkan.

b) Kelembaban Pasir (ASTM C 566-89)

Diperoleh hasil rata-rata sebesar 2,56 \%. ASTM C 566 - 89 yang diperbolehkan kelembaban pasir sebesar $<0,1 \%$ maka agregat halus tersebut tidak memenuhi persyaratan

c) BeratJ enisPasir (ASTM C 128-78)

Diperoleh hasil sebesar 2,70 \% Berat jenis pasir yang disyaratkan ASTM C 128-78 adalah yang berada dalam batas antara 2,4 sampai dengan $2,7 \mathrm{gr} / \mathrm{dm}^{3}$. Jadi pasir diatas memenuhi syarat yang digunakan.

d) Air Resapan (ASTM C 128-93)

Diperoleh data rata-rata sebesar 2,78 \%. Absorbsi (Penyerapan Air), syarat absorbsi (penyerapan) menurut ASTM adalah 0,2 \% - 2,0\%. Jadi hasil tidak sesuai yang di inginkan.

e) MenentukanBerat Volume Pasir (ASTM C 188-89)

Diperoleh hasil 1,417. Untuk berat volume pasir spesifikasi agregat kasar menurut ASTM C29 yaitu 1,6 - 1,9 kg/liter. Jadi hasil tidak sesuai dengan yang di inginkan.

\subsection{Pengujian Agregat Kasar}

a) Test Kondisi Analisa Ayakan Batu Pecah (ASTM C 136-95a)

Diperoleh hasil sebesar 3,33\%. Modulus Halus Butir (HMB), modulus kehalusan butir (Fineness Modulus) atau MHB. Spesifikasi modulus halus butiran agregat kasar menurut ASTM yaitu 5,5\% - 8,5\%. Jadi hasil tidak sesuai yang diinginkan.

b) Kelembapan Kerikil (ASTM C 566-89)

diperoleh data rata-rata sebesar 1,25. Kadar air agregat kasar, spesifikasi kadar air agregat kasar menurut ASTM yaitu 0,5\%-2,0\%, jadi data tersebut memenuhi yang di inginkan.

c) Berat Jenis Kerikil (ASTM C 127-88-93)

Diperoleh data sebesar 2,414. Berdasarkan ASTM C 128-78 berat jenis kerikil yang disyaratkan adalah 2,4 sampai dengan $2,7 \mathrm{gr} / \mathrm{dm}^{3}$. Jadi kerikil diatas memenuhi syarat untuk diggunakan.

d) Air Resapan Kerikil (ASTM C 127-88-93)

Diperoleh hasil rata-rata 1,2\%. Kadar air agregat kasar, spesifikasi kadar air agregat kasar menurut ASTM yaitu $1 \%-2,0 \%$. Jadi hasil memenuhi yang di inginkan.

e) Berat Volume Batu Pecah (ASTM C 29-91)

Berat volume rata-rata dari percobaan diatas yaitu 1,445. Syarat berat volume menurut ASTM C 29 - 91 yaitu antara 1,4 sampai 1,7. Jadi hasil memenuhi yang di inginkan. 


\subsection{Pembuatan Abu Serabut kelapa}

Pembuatan abu serabut kelapa yang nantinya untuk pembuatan beton.

a. Pemisahan Tempurung Dengan Sabut Kelapa

Memisahkan serabut kelapa yang nantinya akan dilakukan proses penjemuran sebelum dilakukan proses pembakaran.

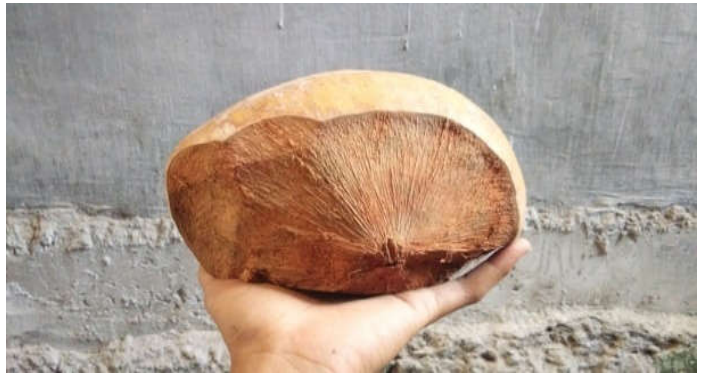

Gambar 1. Pemisahan Tempurung Dengan Sabut Kelapa

b. Penjemuran Serabut Kelapa

Melakukan penjemuran agar sarabut kelapa kering dan untuk mempermudah proses pembakaran.

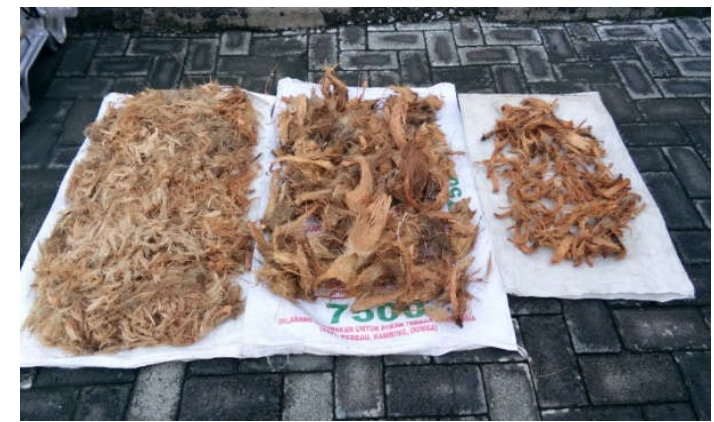

Gambar 2 Penjemura Serabut Kelapa

c. Pembakaran serabut kelapa

Melakukan pembakaran serabut kelapa yang nantinya akan diambil sebagai bahan tambah pada beton.

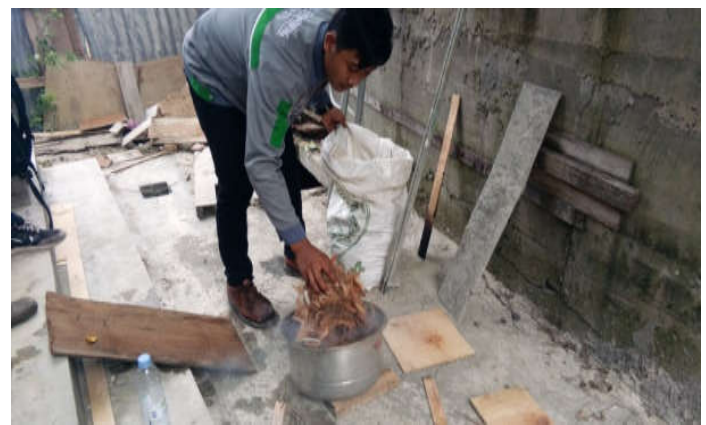

Gambar 3 Pembakaran Serabut Kelapa 


\subsection{Uji Kuat Tekan}

Uji kuat tekan dilakukan di Laboratorium Teknik Sipil Universitas Islam Lamongan untuk mengetahui komposisi campuran yang tepat untuk mengetahui campuran yang paling baik dengan bahan tambah abu serabut kelapa sebagai bahan tambah untuk campuranbeton dengan umur 7 hari.

Untuk memperoleh nilai kuat tekan beton $(\sigma)$ digunakan rumus

Digunakan rumus : $\alpha=\frac{\mathrm{A}}{\mathrm{p}}$

$$
\begin{aligned}
\text { Dimana }: \sigma & =\text { Kuat Tekan benda uji }\left(\mathrm{kg} / \mathrm{cm}^{2}\right) \\
\mathrm{P} & =\text { Beban maksimum }(\mathrm{kg}) \\
\mathrm{A} & =\text { Luas Penampang }\left(\mathrm{cm}^{2}\right)
\end{aligned}
$$

Ket : $\quad \mathrm{A}=$ Beton Normal

$$
\begin{aligned}
& \text { B }=\text { Campuran Abu Serabut Kelapa 0,25\% } \\
& \text { C }=\text { Campuran Abu Serabut Kelapa 0,50 \% } \\
& \text { D }=\text { Campuran Abu Serabut Kelapa 0,75\% }
\end{aligned}
$$

\begin{tabular}{|c|c|c|c|c|c|}
\hline \multirow{2}{*}{ Kode Beton } & \multirow{2}{*}{$\begin{array}{c}\text { Tegangan Hancur } \\
\left(\mathrm{kg} / \mathrm{cm}^{2}\right)\end{array}$} & FaktorKorelasi & Teg. 28 hari & Teg. Hancur & \multirow{2}{*}{ Rata - rata (Mpa) } \\
\cline { 4 - 5 } & & & & 28 hari (Mpa) & \\
\hline A I & 90,58 & 0,65 & 139,35 & 13,670 & \multirow{2}{*}{15,095} \\
\hline A II & 101,91 & 0,65 & 156,78 & 15,380 & \\
\hline A III & 107,57 & 0,65 & 165,49 & 16,235 & \multirow{2}{*}{21,076} \\
\hline B I & 135,88 & 0,65 & 209,04 & 20,507 & \\
\hline B II & 124,55 & 0,65 & 191,61 & 18,797 & \multirow{2}{*}{22,5} \\
\hline B III & 158,52 & 0,65 & 243,87 & 23,924 & \\
\hline C I & 141,54 & 0,65 & 217,75 & 21,361 & \multirow{2}{*}{22,148} \\
\hline C II & 141,54 & 0,65 & 217,75 & 21,361 & \\
\hline C III & 164,18 & 0,65 & 252,58 & 24,778 & \\
\hline D I & 151,54 & 0,65 & 233,13 & 22,870 & \\
\hline D II & 135,88 & 0,65 & 209,04 & 20,507 & \\
\hline D III & 152,86 & 0,65 & 235,16 & 23,069 & \\
\hline
\end{tabular}

Sumber : Hasil Penelitian

Dari tabel 1 diperoleh hasil kuat tekan rata-rata beton normal 15,095 MPa, dengan campuran abu serabut kelapa $0,25 \%$ diperoleh 21,076, campuran $0,50 \%$ diperoleh 22,5 , dan campuran $0,75 \%$ diperoleh 22,148

Tabel 2 Data Tegangan Karakteristik 28 hari

\begin{tabular}{|c|c|c|c|c|}
\hline $\begin{array}{c}\text { Teg. Hancur } \\
\text { (kg/cm2) }\end{array}$ & $\begin{array}{c}\text { Tegangan } \\
\text { Hancur } \\
\text { (MPa) }\end{array}$ & $\begin{array}{c}\text { (Teghancur - } \\
\text { teg rata2) }\end{array}$ & $\begin{array}{c}\text { Standar } \\
\text { deviasi }\end{array}$ & $\begin{array}{c}\text { Tegangan } \\
\text { Karakteristikotbk }\end{array}$ \\
\hline A I & 13,670 & 2,030 & 1,306 & 16,505 \\
\hline
\end{tabular}




\begin{tabular}{|c|c|c|c|c|}
\hline A II & 15,380 & 0,081 & 1,306 & 16,505 \\
\hline A III & 16,235 & 1,299 & 1,306 & 16,505 \\
\hline B I & 20,507 & 0,324 & 2,610 & 23,895 \\
\hline B II & 18,797 & 5,193 & 2,610 & 23,895 \\
\hline B III & 23,924 & 8,110 & 2,610 & 23,895 \\
\hline C I & 21,361 & 1,297 & 1,070 & 23,656 \\
\hline C II & 21,36 & 1,297 & 1,070 & 23,656 \\
\hline C III & 24,778 & 5,189 & 1,070 & 23,656 \\
\hline D I & 22,870 & 0,520 & 1,425 & 23,688 \\
\hline D II & 20,507 & 2,696 & 1,425 & 23,688 \\
\hline D III & 23,069 & 0,847 & 1,425 & 23,688 \\
\hline
\end{tabular}

Sumber : Hasil Penelitian

Dari tabel 2 diperoleh hasil tegangan karakteristik beton normal $\mathrm{MPa}$, dengan campuran abu serabut kelapa 0,25\% diperoleh 23,895 $\mathrm{MPa}$, campuran 0,5\% diperoleh 23,656 $\mathrm{MPa}$, dan campuran $0,75 \%$ diperoleh $23,688 \mathrm{Mpa}$

\section{Grafik Data Kuat Tekan}

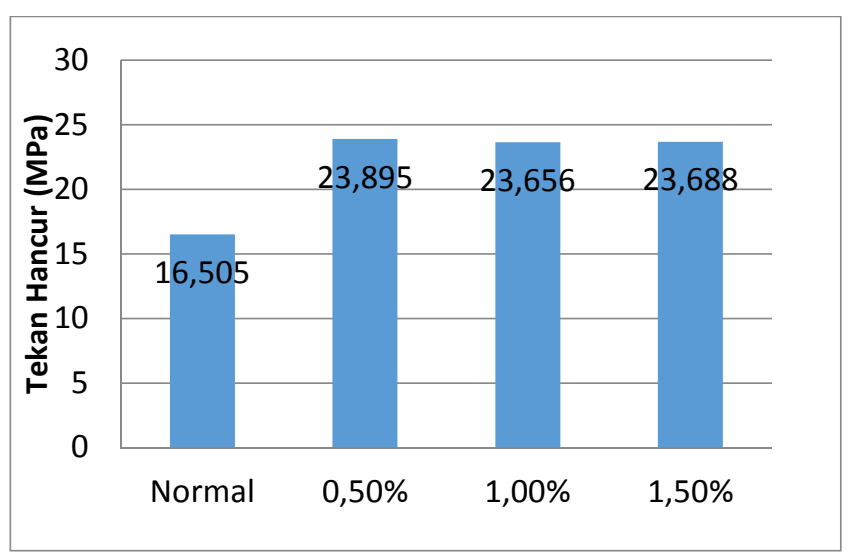

Sumber : Hasil Penelitian

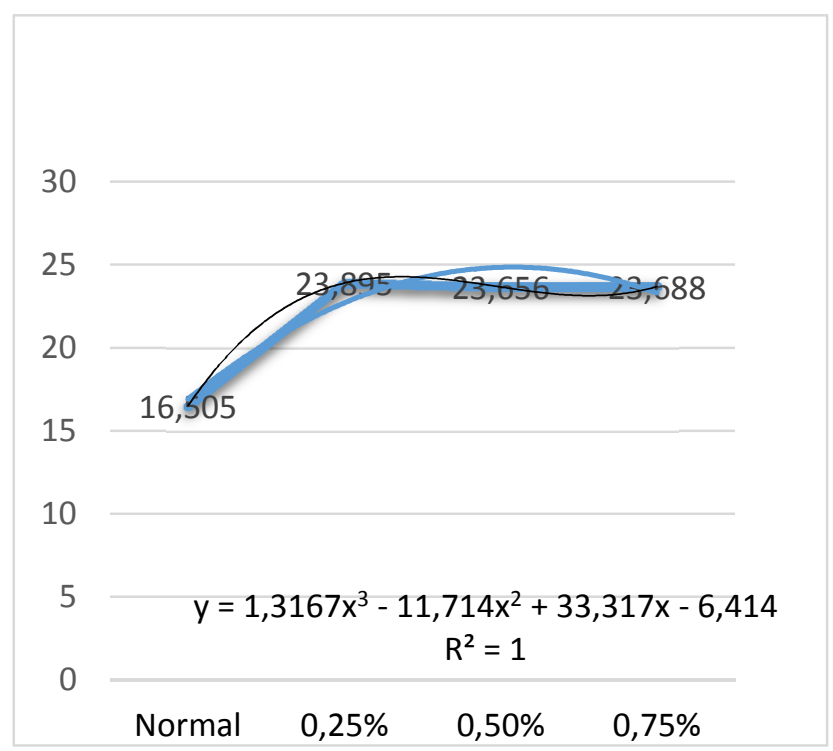


Sumber : Hasil Peneliti

diperoleh grafik hubungan non linier pengaruh penambahan abu serabut kelapa terhadap kuat tekan beton terhadap kuat tekan dengan grafik

polinema orde 2 diperoleh persamaan $y=1,316 x^{3}-11,71 x^{2}+33,31 x-6,414$ dengan $R^{2}=1$.

\section{KESIMPULAN dan SARAN}

\section{Kesimpulan}

Berdasarkan perancangan pembuatan beton dengan penambahan abu serabut kelapa yang telah dilakukan penelitian di Laboratorium Fakultas Teknik Prodi Teknik Sipil Universitas Islam Lamongan, dapat diambil kesimpulan.

1. Pengaruh campuran abu serabut kelapa untuk beton mutu K-100 memepengaruhi kuat tekan dari beton itu sendiri dari data yang telah dilakukan penelitian abu serabut kelapa mengalami kenaikan secara siknifikan, beton normal K-100 kuat tekan yang diperoleh 13,964 MPa, beton campuran abu serabut kelapa 0,25\% mencapai 20,217 MPa, beton campuran abu serabut kelapa 0,50\% mencapai 20,173 MPa, yang paling tinggi beton campuran abu serabut kelapa 0,75 \% dapat mencapai kuat tekan 20,041 MPa. Dari sini dapat ditarik kesimpulan bahwa abu serabut kelapa bisa dijadikan untuk bahan tambah semen pada beton mutu K-100 pada presentasi diatas.

\section{Saran}

Dari penelitian penambahan abu serabut kelapa sebagai bahan tambah untuk kuat tekan beton adalah:

1. Perlu dilakukan penelitian lebih lanjut dengan pengujian kuat tarik beton yang belum dilakukan dalam penelitian ini.

2. Untuk penelitian lebih lanjut perlu diperhatikan untuk penggunan agregat yang digunakan baik agregat halus maupun kasar yang merupakan komponen utama pembuatan beton dalam keadaan SSD, sebelum penelitian berlangsung kita perlu memberikan wadah atau tempat untuk penyimpanan agregat sementara agar tidak terkena hujan yang akan memepengaruhi keadaan SSD agregat.

\section{DAFTAR PUSTAKA}

[1] ASTM C 29 - 91 Standart Test Method for Bulk Density (Until weight) and Voids Aggregates

[2] ASTM C 128 - 78 Standart Test Methodfor Density, Relative Density (Spesific Gravity, and Absorbtion of Fine Aggregate

[3] ASTM C 187 - 86 Normal Consistency of Hydraulic Cement

[4] ASTM C 566 - 89 Standart Test Method for Total Evaporable Moisture Concret of Aggregate by Drying 
[5] Candra, A. I. (n.d.). ANALISIS DAYA DUKUNG PONDASI STROUS PILE PADA PEMBANGUNAN GEDUNG MINI HOSPITAL UNIVERSITAS KADIRI Agata. Ukarst, 1, 63-70.

[6] Candra, A. I., Gardjito, E., Cahyo, Y., \& Prasetyo, G. A. (2019). Pemanfaatan Limbah Puntung Rokok Filter Sebagai Bahan Campuran Beton Ringan Berpori. UKaRsT, 3(1), 82-89.

[7] Standart Nasional Indonesia S 04-1989-F Pemakaian Air Untuk Beton. Badan Standarisasi Nasional.

[8] Standart Nasional Indonesia SK-SNI S-18-1990-03, Penyusun Beton.

[9] Standart Nasional Indonesia SNI 03-1974-1990, Metode Pengujian Kuat Tekan Beton

[10] Sukirman, S., 1992. "Perkerasaan Lentur Jalan Raya", Bandung.

[11] Zaenuri, M., Romadhon, R., Gunarto, A., \& Cahyono, A. (2018). PENELITIAN PENGGUNAAN BATU GAMPING SEBAGAI AGREGAT KASAR DAN FILLER PADA ASPAL CAMPURAN AC-BC. UKaRsT, 2(1), 24-35.

[12] Badan Standarisasi Nasional, BSSNI,2011. SKSNI 2434-2011. Tentang Cara Uji Titik Lembek Aspal Dengan Alat Cincin Dan Bola (Ring And Ball)

[13] Ahmad Bagir dan Gigih Eka Pradana., 2011.Pemanfaatan Serat Eceng Gondok

[14] Badan Standarisasi Nasional, 2012. SNI ASTM C136:2012 : Metode uji untuk analisis saringan agregat halus dan agregat kasar. Jakarta: BSN.

[15] Badan Standarisasi Nasional, SNI 8129:2015 tentang Spesifikasi Stone Matrix Asphalt (SMA) 